\title{
Research Paper \\ The Antioxidant Effects of Ginger Extract on Bioavailability and Oxidative Stress-induced Apoptosis in Mesenchymal Stem Cells of Human Adipose Tis- sue and Rat Bone Marrow
}

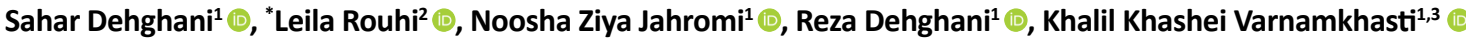

1. Department of Biochemistry, Shahrekord Branch, University of Islamic Azad, Shahrekord, Iran.

2. Department of Physiology, Shahrekord Branch, University of Islamic Azad, Shahrekord, Iran.

3. Department of Genetics, School of Medicine, University of Islamic Azad, Kazerun, Iran.

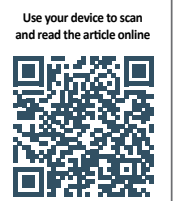

Citation: Dehghani S, Rouhi L, Ziya Jahromi N, Dehghani R, Khashei Varnamkhasti Kh. [The Antioxidant Effects of Ginger Extract on Bioavailability and Oxidative Stress-induced Apoptosis in Mesenchymal Stem Cells of Human Adipose Tissue and Rat Bone Marrow (Persian)]. Journal of Arak University of Medical Sciences (JAMS). 2021; 24(2):216-229. https://doi.org/10.32598/ JAMS.24.2.6146.4

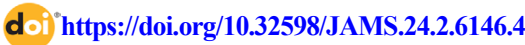

Key words:

Ginger extract, Oxidative stress, Antioxidant, Mesenchymal stem cells, Apoptosis, Cytotoxicity

\section{ABSTRACT}

Background and Aim Proliferate potential differentiate into different cell lineages and high self-renewal of Mesenchymal Stem Cells (MSCs); thus, they are ideal tools for regenerative medicine. However, a leading problem is an oxidative stress in the target tissue and the apoptosis of transplanted stem cells before tissue repair. The pretreatment of stem cells with antioxidants may make them resistant to oxidative stress. Ginger is the main medicinal plant with antioxidant properties. This study explored the antioxidant effects of ginger extract on bioavailability and oxidative stress-induced apoptosis in human adipose tissue-derived mesenchymal stem cells and rat bone marrow examined.

Methods \& Materials In this study, human adipose tissue-derived mesenchymal stem cells and rat bone marrow were cultured in a DMEM medium with $20 \%$ FBS. The explored cells were incubated for 4 and 6 hours for pretreatment with different concentrations of ginger extract (50, 100, 200, \& $400 \mathrm{mg} / \mathrm{mL}$ ); then, they were treated with $200 \mu \mathrm{M} \mathrm{H}_{2} \mathrm{O}_{2}$ for 2 hours. Bioavailability was analyzed by ELISA reader using an MTS kit and apoptosis was analyzed by flow cytometry using an Annexin V-FITC/PI kit into the manufacturer's protocol at both times. The obtained data were analyzed by Analysis of Variance (ANOVA) using SPSS.

Ethical Considerations This study was approved by the Ethics Research Committee of Shahrekord Branch, Islamic Azad University (Code: IR.IAU.SHK.REC.1397.028).

Results The MTS results indicated a dose- and time-dependent manner increase in the bioavailability of human adipose tissue-derived mesenchymal treated stem cells. Ginger extract treatment also dose- and time-dependently decreased the rate of apoptosis in rat bone marrow mesenchymal stem cells.

Conclusion Ginger extract, by reducing the oxidative stress in mesenchymal stem cells, elevates their lifespan in the target tissue, and increases the efficiency of these cells in tissue regeneration.

\section{Extended Abstract}

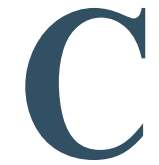

\section{Introduction}

ell therapy is a subset of restorative medicine. Moreover, stem cells are the first hope for the repair of damaged tissues $[3,4]$. Concerning origin, these cells are divided into two main categories of embryonic stem cells and adult stem cells [5]. Due to some limitations in the production and use of embryonic stem cells, in recent years, a new wave of research on adult stem cells has begun, i.e., extensively performed [6]. Mes-

\section{* Corresponding Author}

Leila Rouhi

Address: Department of Physiology, Shahrekord Branch, University of Islamic Azad, Shahrekord, Iran.

Tel: +98 (912) 6043305

E-mail: irouhi59@gmail.com 


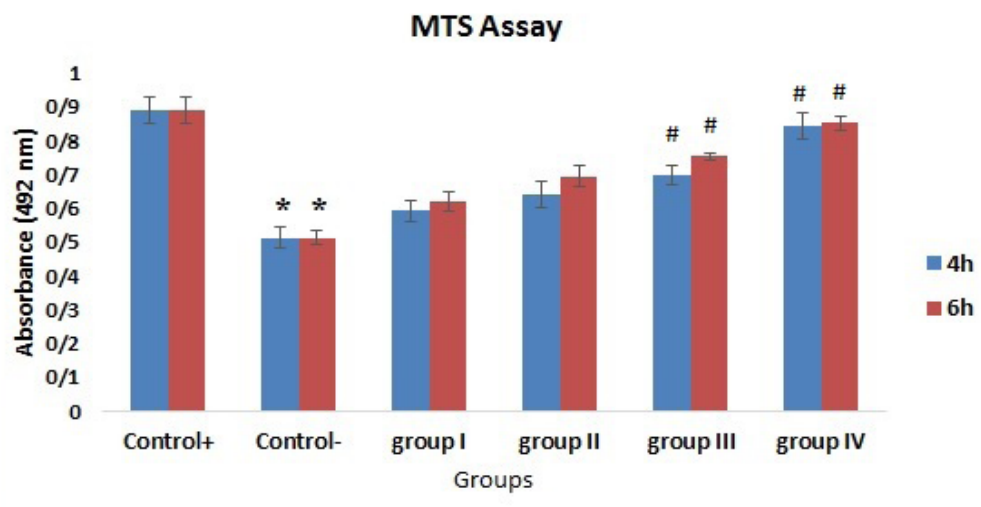

Figure 1. The frequency of viable cells in human adipose tissue-derived MSCs treated with different concentrations of ginger extract for 4 and 6 hours

* $\mathrm{P} \leq 0.05$ compared with the positive control group (cells exposed to culture medium), ${ }^{\#} \mathrm{P} \leq 0.05$ compared with the negative control group (cells exposed to $\mathrm{H}_{2} \mathrm{O}_{2}$ ).

enchymal Stem Cells (MSCs), as major adult stem cells, can differentiate into cells that are not mesenchymal derivatives [7]. However, due to the unfavorable conditions of the transplant recipient, including hypoxia and the presence of oxygen-free radicals that activate and increase aging factors by causing stress in the cell, eventually leading to apoptosis and cell death, most of the transplanted mesenchymal stem cells are lost in the early days; which in turn, this condition reduces their efficiency $[12,13]$. Studies attempted to identify and use factors that prevent oxidative stress in these cells. One of these characteristics included antioxidants [14]. Ginger, with the scientific name of Zingiber officinale, is a medicinal plant with pharmacological properties, such as antioxidant, anti-apoptotic, and anti-inflammatory effects [18]. Therefore, the present study aimed to explore the antioxidant effect of ginger extract on cytotoxicity and the induction of apoptosis due to oxidative stress in human adipose tissue-derived MSCs and rat bone marrow.

\section{Materials and Methods}

In this study, human Adipose Tissue Mesenchymal Stem Cells (AD-MSCs) were obtained from the National Center for Genetic and Biological Resources of Iran and rat bone marrow mesenchymal stem cells were extracted from the tibia and femur of rats. Cells in Dulbecco's Modified Eagle Medium (DMEM) culture medium (Gibco, USA) containing 20\% Foetal Bovine Serum (FBS) (Gibco, USA) and $1 \%$ Penicillin-Streptomycin (Penstrep) (Gibco, USA) in an incubator (Memmert, Germany) were cultured in flask 75 with $5 \% \mathrm{CO}_{2}$ gas pressure, $90 \%$ humidity, and at $37^{\circ} \mathrm{C}$. The culture medium was changed three times a week and tryp$\sin /$ EDTA solution was used to harvest the cells. To prepare the ginger extract, 500 gr of the dried ginger plant was prepared and after grinding, the resulting powder was placed in $96 \%$ alcohol for 10 days to dissolve its active ingredients in alcohol. The contents of the filter paper and the solution obtained by the rotary apparatus were then concentrated at $50^{\circ} \mathrm{C}$ and $60 \mathrm{rpm} . \mathrm{H}_{2} \mathrm{O}_{2}$ was prepared in liquid form. The assay of human adipose tissue-derived MSCs was evaluated using MTS colorimetric method. The status of apoptosis in rat bone marrow-derived MSCs were also explored by Annexin V-FITC/PI test.

\section{Results}

The effects of ginger extract on cytotoxicity induced by oxidative stress in human adipose tissue-derived MSCs. Oxidative stress-induced cytotoxicity in human adipose tissue-derived MSCs treated with different concentrations of ginger extract $(50,100,200 \& 400 \mathrm{mg} / \mathrm{mL})$, after incubation periods ( $4 \& 6$ hours with ginger extract $\& 2$ hours with $\mathrm{H}_{2} \mathrm{O}_{2}$ ) were evaluated using MTS test. The obtained results indicated that ginger extract could increase the bioavailability of human adipose tissue-derived MSCs in a dose- and time-dependent manner $(\mathrm{P} \leq 0.022 *)$ (Figure 1).

The effects of ginger extract on the induction of oxidative stress-induced apoptosis in rat bone marrow-derived MSCs

Annexin V-FITS test was applied to evaluate the induction of apoptosis. The relevant results suggested a dose- and time-dependent reduction in the frequency of death in bone marrow-derived MSCs in the treated experimental groups. 

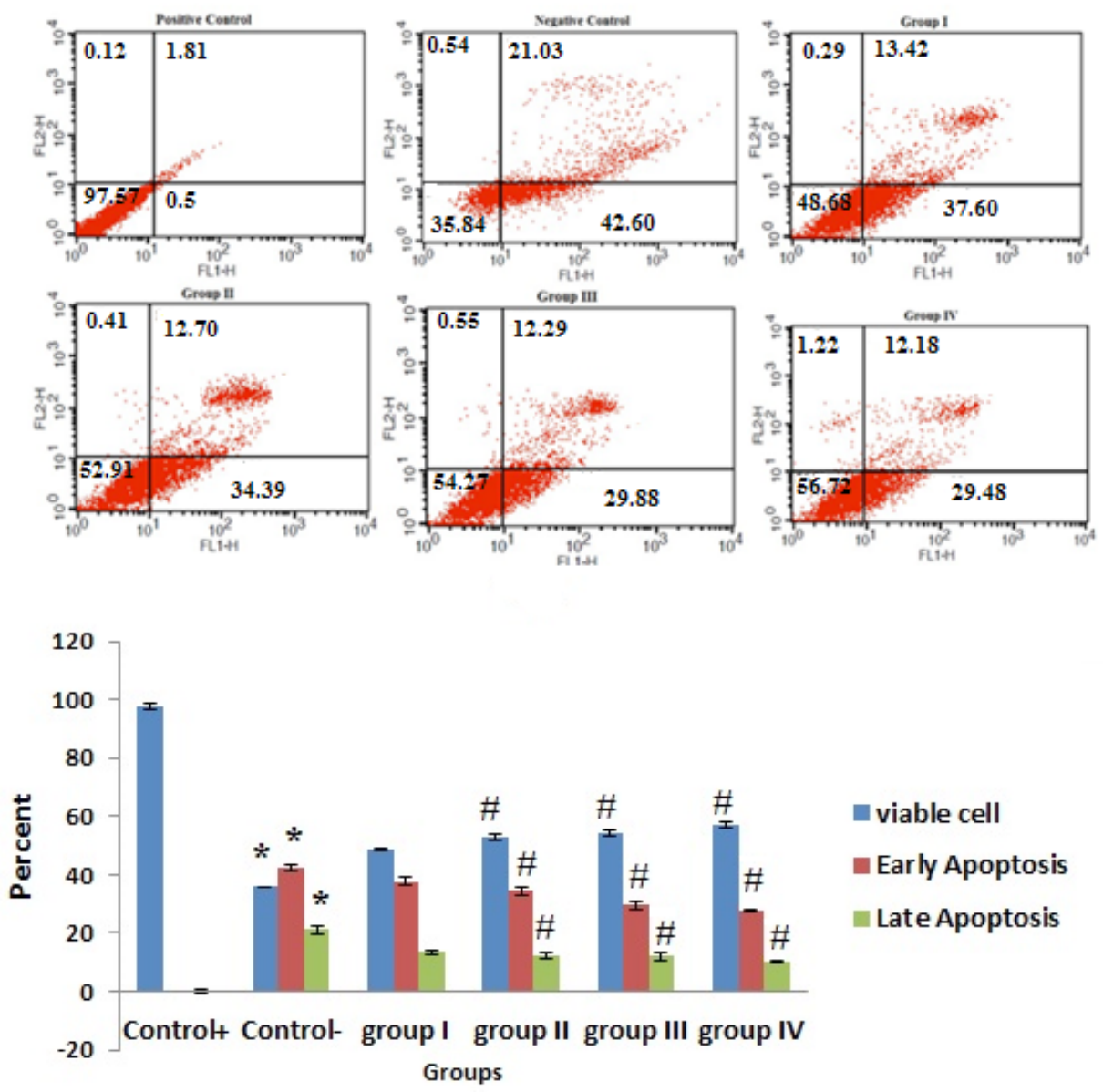

Late Apoptosis

Groups

\section{Journal of}

Journal of
Arak University of Medical Sciences

Figure 2. The frequency of viable cells, primary apoptosis, and late apoptosis in bone marrow-derived MSCs of the rats treated with different concentrations of ginger extract for 4 hours

${ }^{*} \mathrm{P} \leq 0.05$ compared to the positive control group (cells exposed to culture medium), ${ }^{\#} \mathrm{P} \leq 0.05$ compared to the negative control group (cells exposed to $\mathrm{H}_{2} \mathrm{O}_{2}$ ).

As illustrated in Figure 2, in the 4-hour treatment, the frequency of cells in the early stages of apoptosis increased from $37.60 \%$ at $50 \mathrm{mg} / \mathrm{mL}$ to $29.48 \%$ at 400 . Such a decrease in the frequency of apoptosis in all concentrations was significantly different from that of the negative control group. Furthermore, the frequency of cells in the late stages of apoptosis decreased with the increasing dose of ginger extract, from $13.42 \%$ at a concentration of $50 \mathrm{mg} /$ $\mathrm{mL}$ to $12.18 \%$ at a concentration of $400 \mathrm{mg} / \mathrm{mL}$, i.e., also a significant decrease in all concentrations, compared to the negative control group $(\mathrm{P} \leq 0.030)$ (Figure 2).

Furthermore, in the 6-hour treatment, the frequency of cells in the early stages of apoptosis increased from $23.67 \%$ at a concentration of $50 \mathrm{mg} / \mathrm{mL}$ to $21.59 \%$ at a concentration of $400 \mathrm{mg} / \mathrm{mL}$. This decrease in the frequency of apoptosis in all concentrations significantly differed from that of the negative control group. In addition, the frequency of cells in the late stages of apoptosis decreased with increasing dose and treatment time with ginger extract, from $12.98 \%$ at a concentration of $50 \mathrm{mg} / \mathrm{mL}$ to $15.9 \%$ to 400 $\mathrm{mg} / \mathrm{mL}$, i.e., a significant decrease in the frequency of apoptosis in all concentrations, compared to the negative control group ( $\mathrm{P} \leq 0.016)$ (Figure 3).

\section{Discussion and Conclusion}

During the normal functioning of the cells used in cell therapy, reactive oxygen species are produced that have high reactivity with DNA, proteins, carbohydrates, and lipids; they cause irreparable damage to these macromolecules to enter. Ginger is an essential medicinal plant that has long been used to treat various diseases [19]. The antioxidant effects of ginger have been studied for years. This study explored the antioxidant effects of ginger extract on cytotoxicity and the induction of oxidative stress-induced 

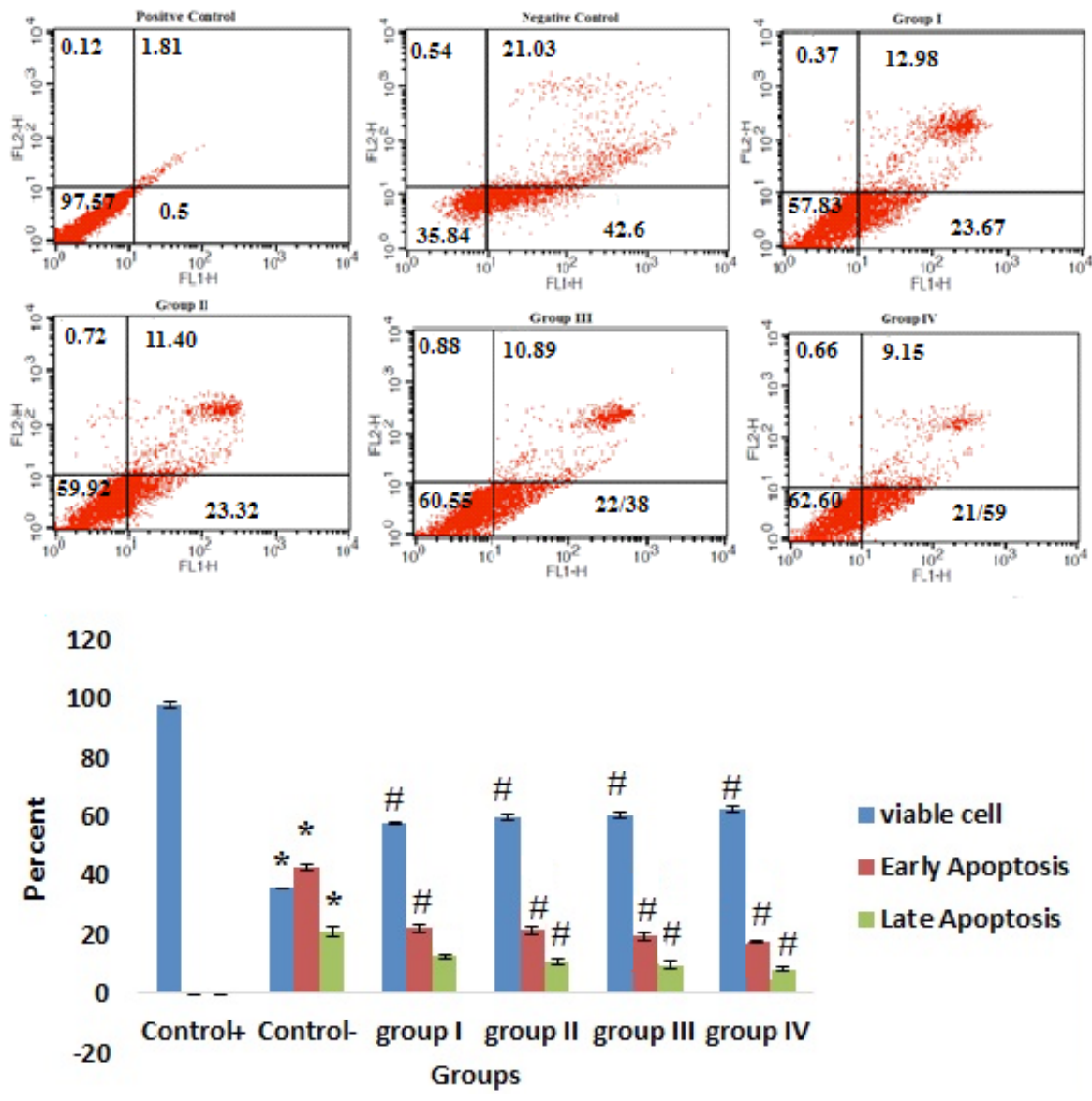

Journal of
Arak University of Medical Sciences

Figure 3. The frequency of viable cells, primary apoptosis, and terminal apoptosis in bone marrow-derived MSCs of rats treated with different concentrations of ginger extract for 6 hours

${ }^{*} \mathrm{P} \leq 0.05$ compared to the positive control group (cells exposed to culture medium), ${ }^{*} \mathrm{P} \leq 0.05$ compared to the negative control group (cells exposed to $\mathrm{H}_{2} \mathrm{O}_{2}$ ).

apoptosis in human adipose tissue-derived MSCs and rat bone marrow. The obtained results indicated that ginger extract reduced the frequency of human adipose tissue-derived MSCs and rat bone marrow by acting as an antioxidant, which further increased the success of using mesenchymal stem cells in the cell treatment.

\section{Ethical Considerations}

\section{Compliance with ethical guidelines}

This study was approved by the Ethics Research Committee of Shahrekord Branch, Islamic Azad University (code: IR.IAU.SHK.REC.1397.028).

\section{Funding}

This study was extracted from the Msc. thesis of the first author at the Department of Biochemistry, Faculty of Science, Shahrekord Branch, Islamic Azad University.

\section{Authors' contributions}

All authors equally contributed to preparing this article.

\section{Conflicts of interest}

The authors declared no conflict of interest.

\section{Acknowledgements}

We would like to thank the esteemed Vice Chancellor for Research of Shahrekord Branch of Azad University and everyone who contributed to this research. 
This Page Intentionally Left Blank 


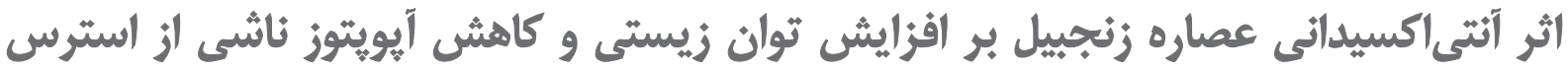

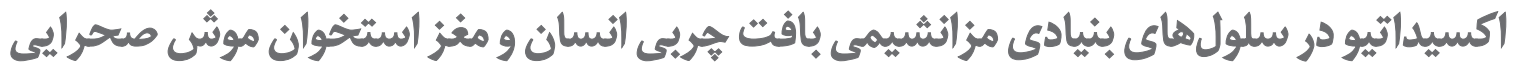

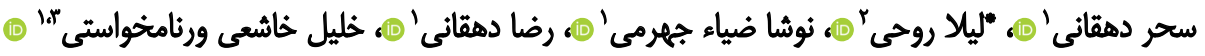

ا. ا. كروه بيوشيمى، دانشكده علوم بايه، واحد شهركرد، دانشكاه آزاداد اسلامى، شهر كرد، ايران.

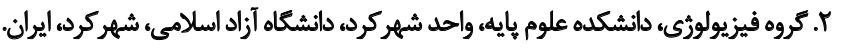

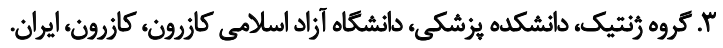

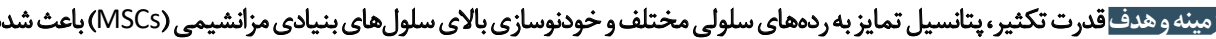

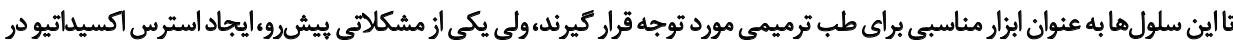

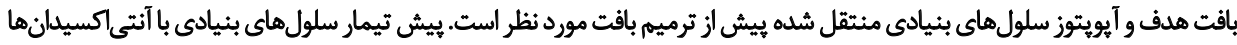

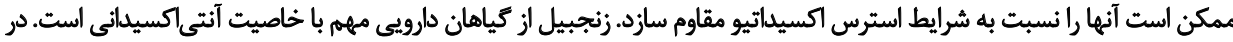

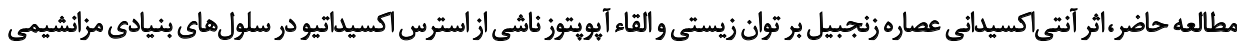

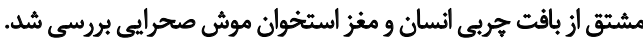

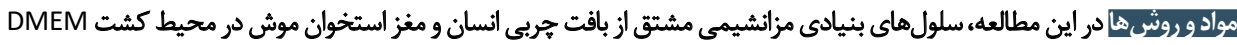

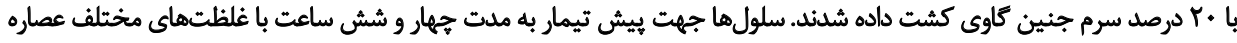

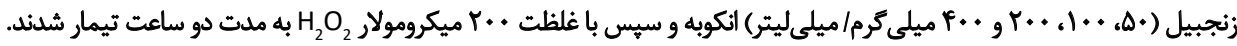

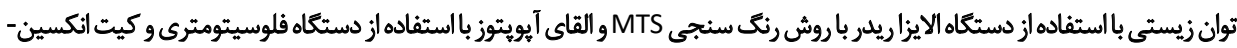

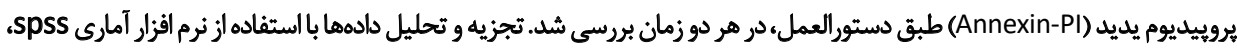

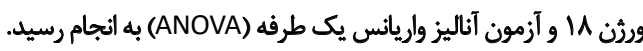

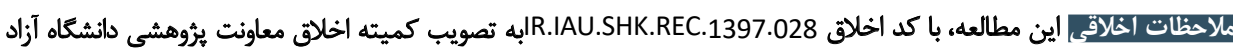

اسلامى واحد شهركرد رسيد.

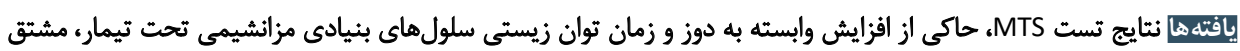

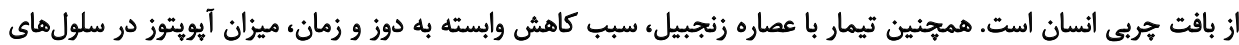

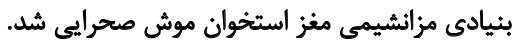

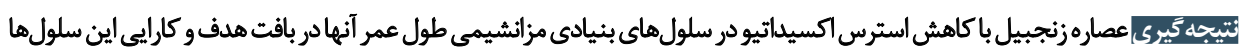

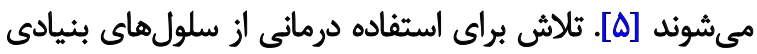

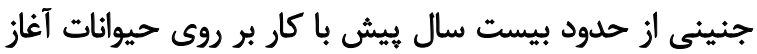

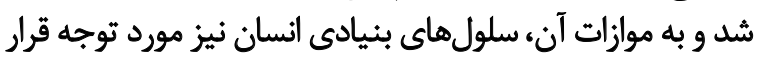

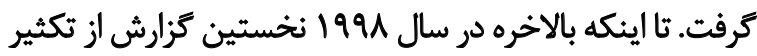

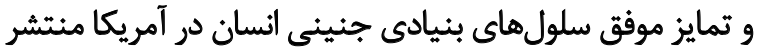

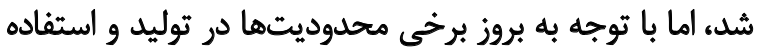

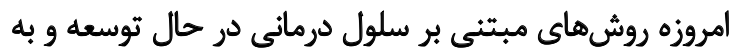

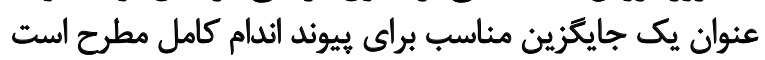

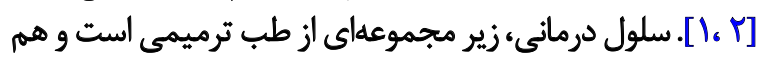

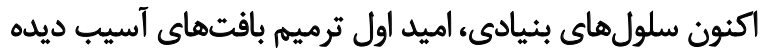

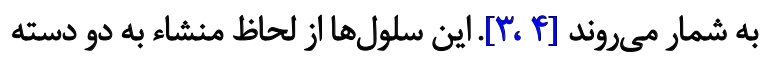

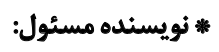

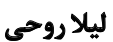
نشائي: شهركرد، دانشعاه آزاد اسلامى، واحد شهركرد، دانشكده علوم ثايه، كروه فيزيولوزئ. + تلفن: يست الكترونيكي: ئهن: irouhi59@gmail.com 
دCOX-2 القاء شده توسط اشعه ماورابنفش است [9 [19]. مطالعات

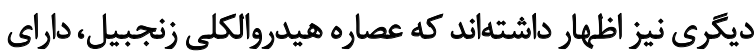

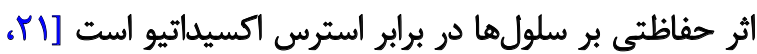

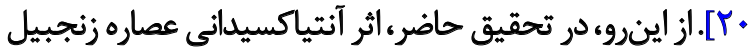

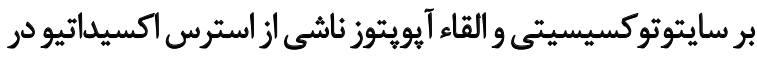

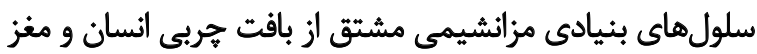
استخوان موش صحرايى مورد بررسى قرار كرفت.

$$
\text { مواد و روش هانها }
$$

ditho go

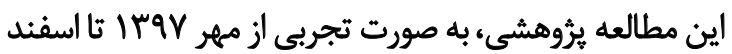

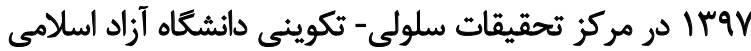

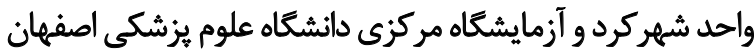

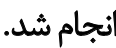

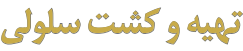

سلولهاى بنيادى مزانشيمى بافت جربى انسان (AD-MSC)

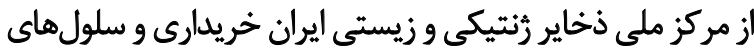

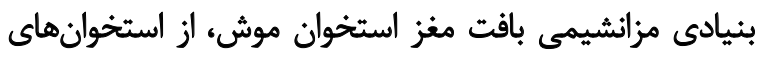

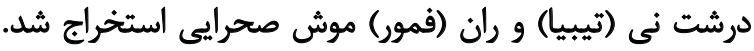

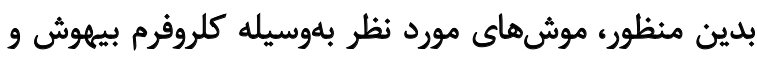

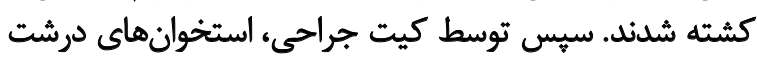

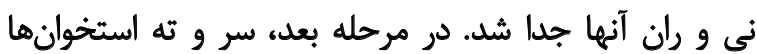

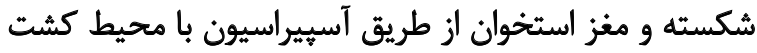

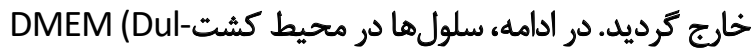
becco's Modified Eagle Medium) (Gibco, USA)

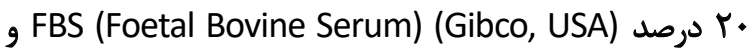
Penstrep (Penicillin-Streptomycin) (Gibco, درصد 1

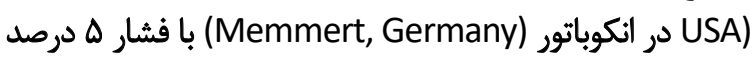
كاز CO

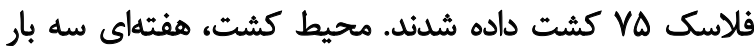

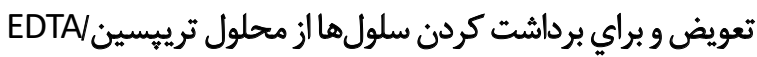

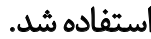

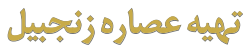

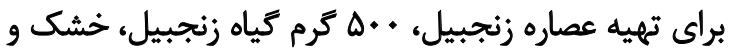

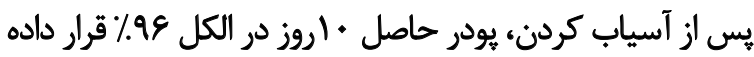

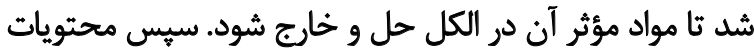

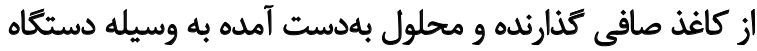

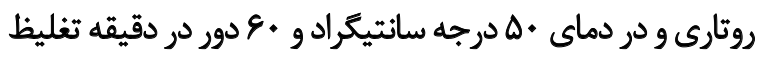

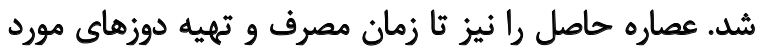

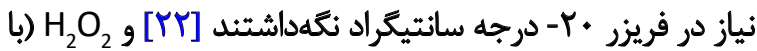
نام تجارى Hydrogen peroxide solution و شرئ شماره محصول
از سلولهاى بنيادى جنينى، در جند سال اخير، موج جديدى بري

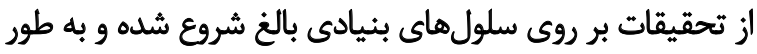

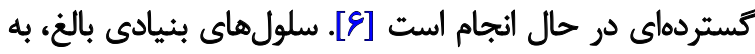

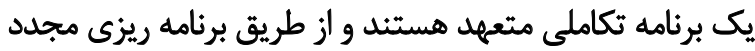

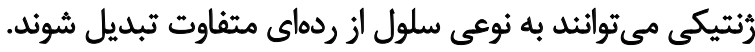

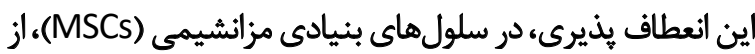

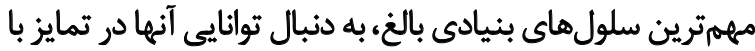

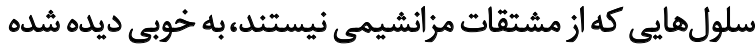

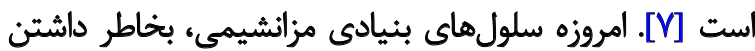

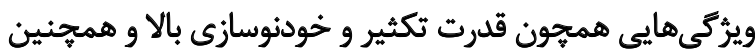

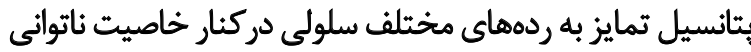

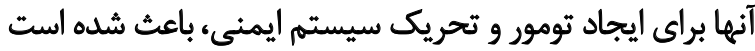

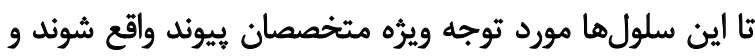

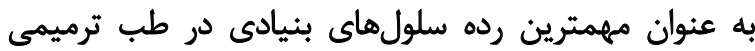

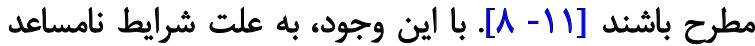

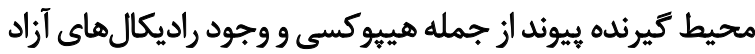

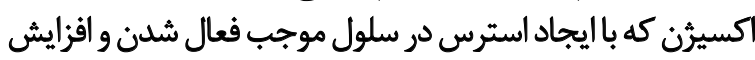

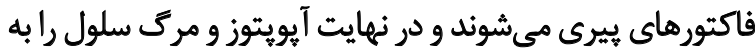

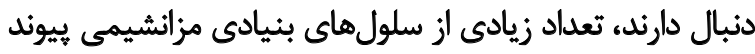

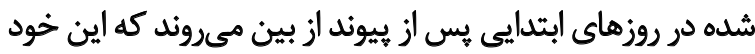

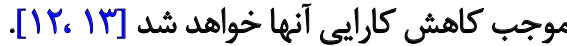

با توجه به اهميت موضوع، به منظور يافتن راههايى براى

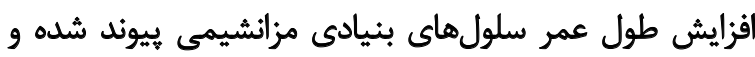

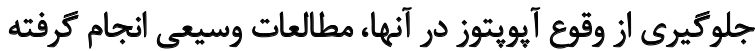

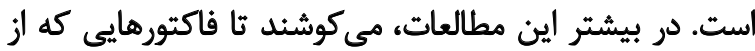

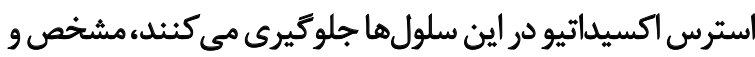

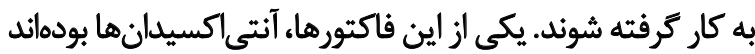

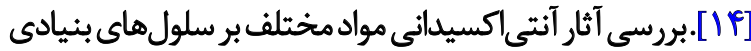

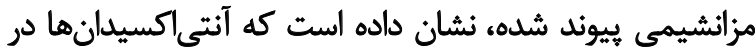

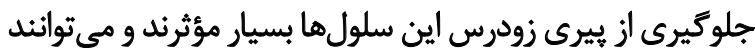

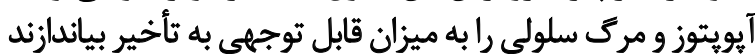

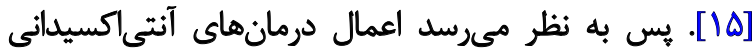

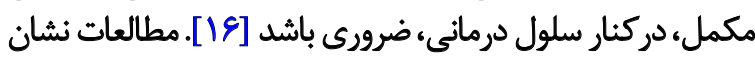

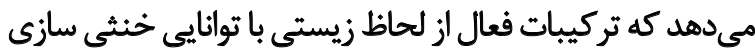

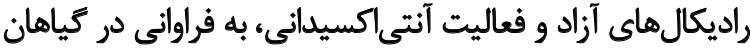

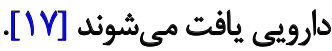

زنجبيل با نام علمى Zingiber officinale از جمله كياهان دارويى با ويزّكى هاى فارماكولوزيكى مانئند اثرات آنتى آنسيداني،

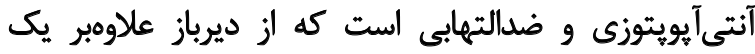

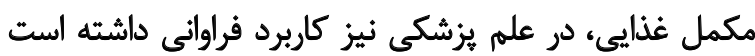

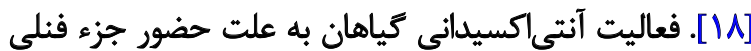

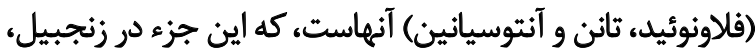

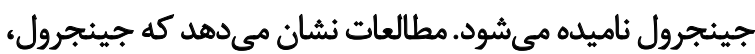
عاملى موثر براى جلوكيرى از توليد كونههاي فعال اكسيرن و بيان 


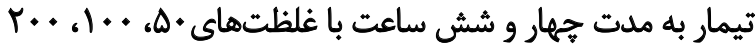

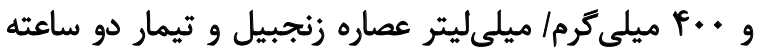

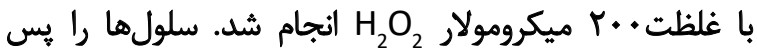
از شستوشو با PBS و آتزيم ترييسين (Gibco، آمريكا) از

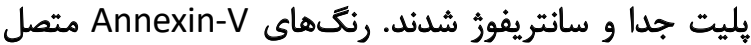

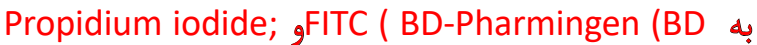
را به ميزان ينج ميكروليتر به مدت BD Pharmingen) ( (PI

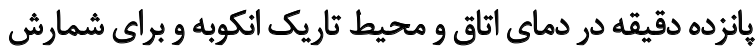
بلوسيله دستكاه فلوسايتومتري (FACS Calibur)، آمريكا)

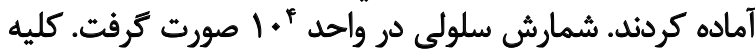
آزمايشها با سه بار تكرار صورت بذيرفت دارت

Syloll

بررسى آمارى دادهها با استفاده از نرم افزار آمارى SPSS، ورثن

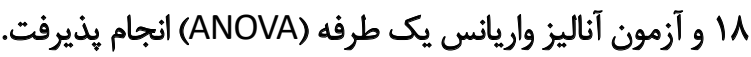

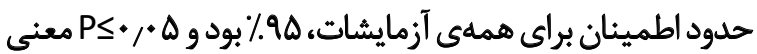
دار محسوب شد شدوند

يافتهها

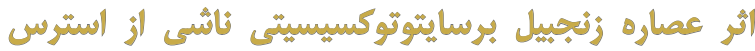

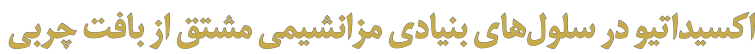

أinl

سايتوتوكسيسيتى ناشى از استرس اكسيداتيو در سلولهاي

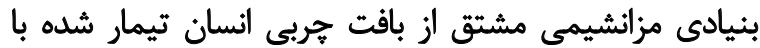

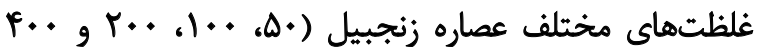

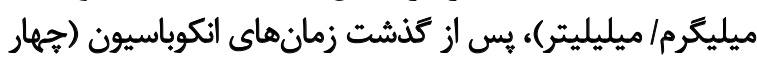

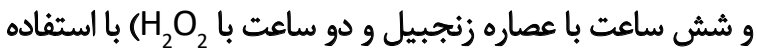
از تست MTS بررسى شد. شنتايج حاصل شده از اين تست نشان دان
SIGMA AL-) به صورت آماده و به حالت مايع (TISVAT (DRICH-

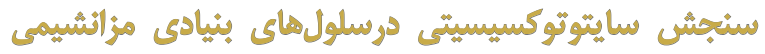

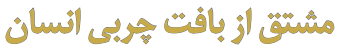

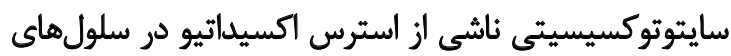

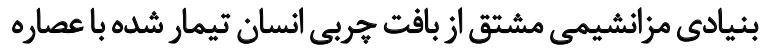

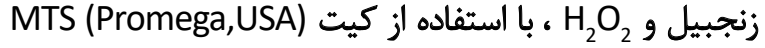

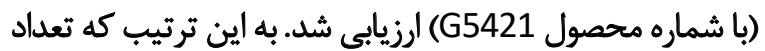

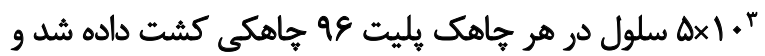

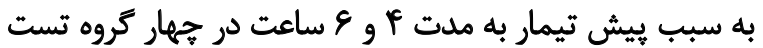

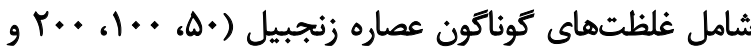

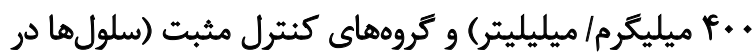

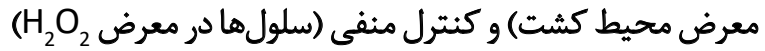

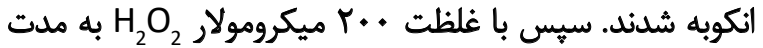

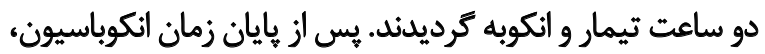

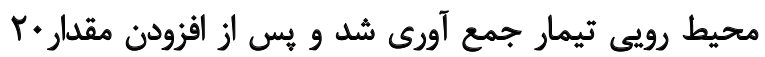

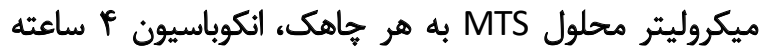

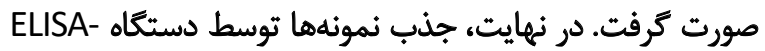
rreader

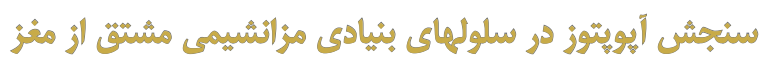

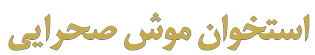

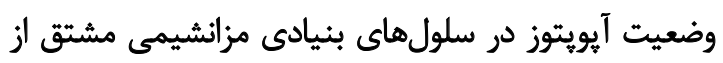

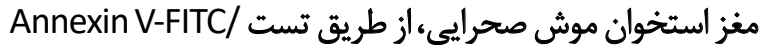

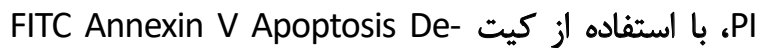
tection kit (BD Pharmingen, USA) (هD\&DFV)

\section{MTS Assay}

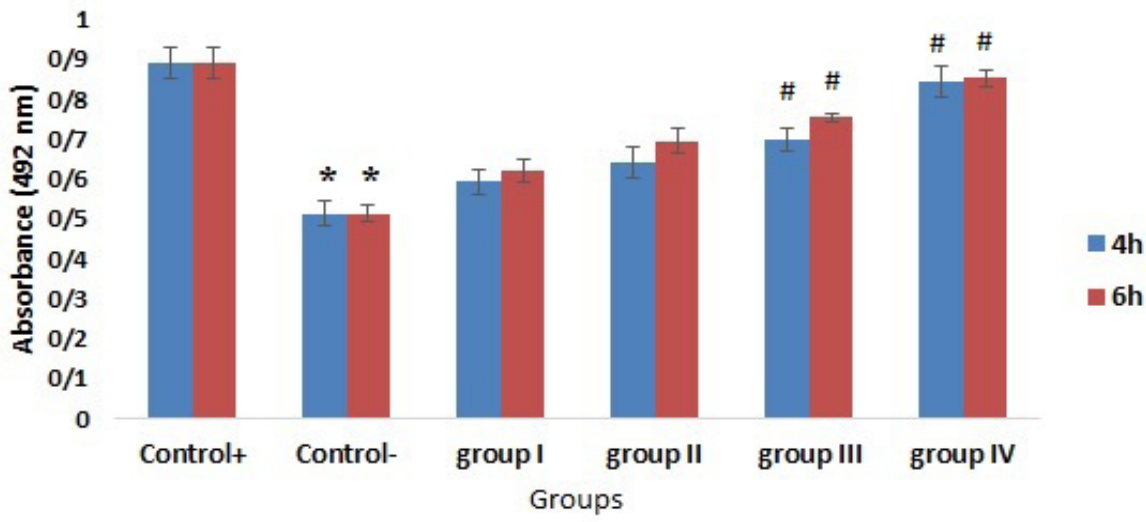

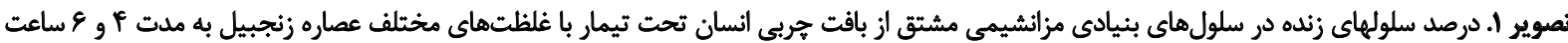

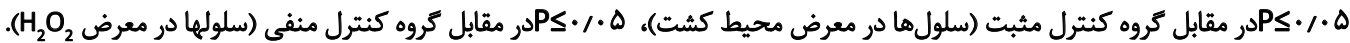



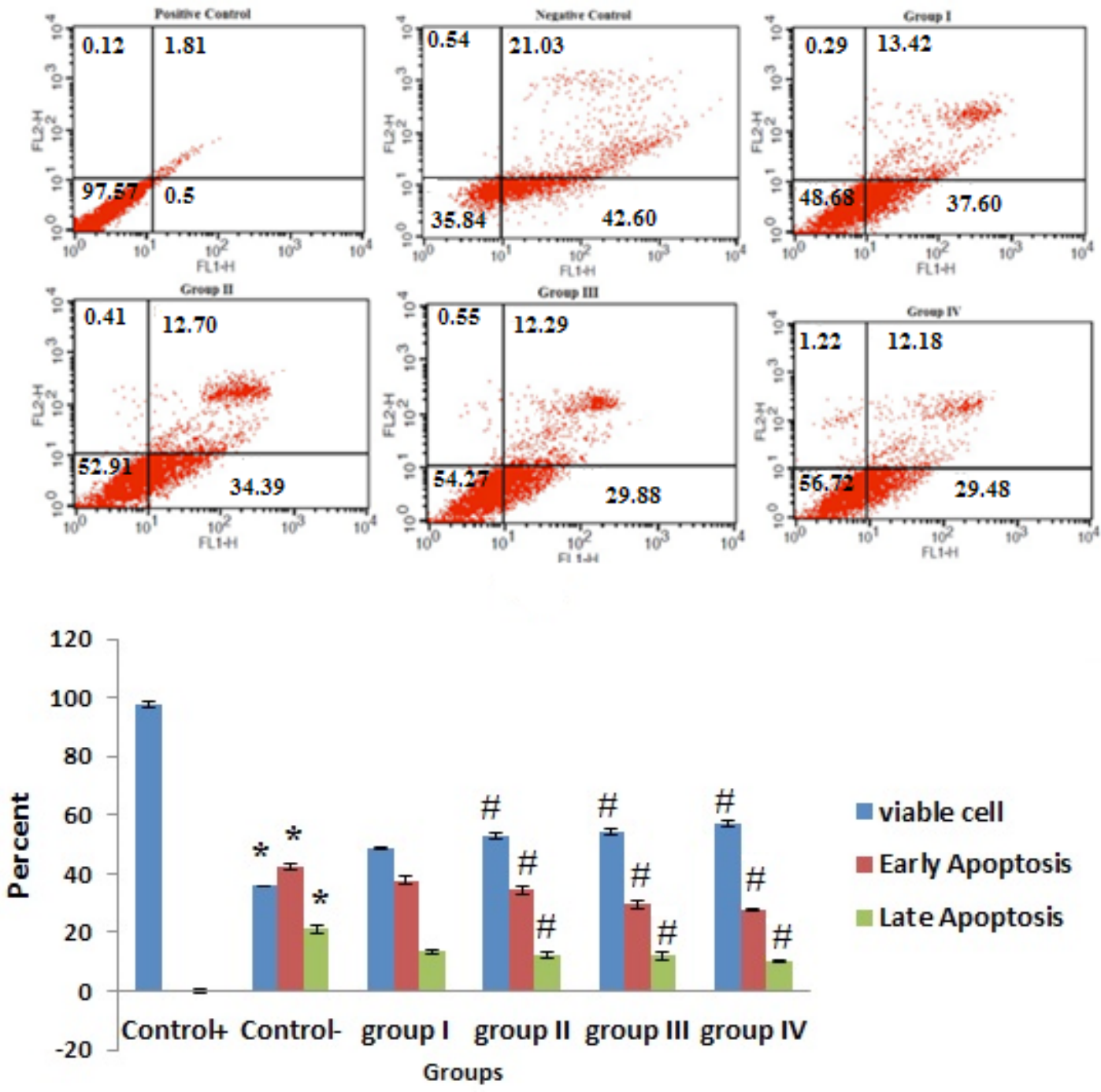

sing

تصوير r. درصد سلولهاى زئده، آيويتوز اوليه و آيويتوز انتهايى در سلولهاى بنيادى مزانشيمى مشتق از مغز استخوان موش صحرايى تحت تيمار با غلظتهاى

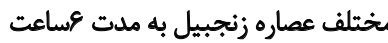

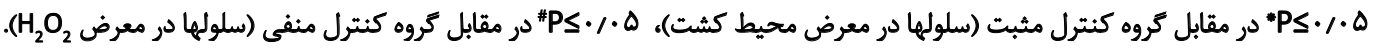

همانوطور كه در تصوير شماره Y ديده مى مئود، در تيمار جهار

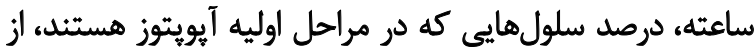
در غلظت دV/\&.

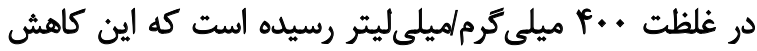

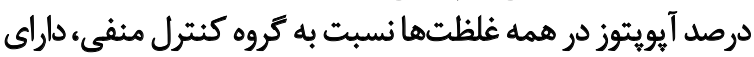

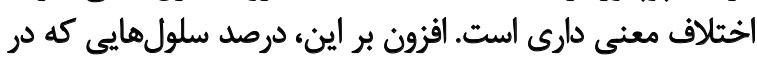

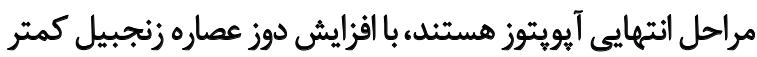

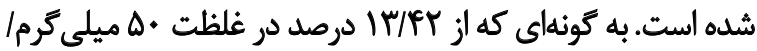

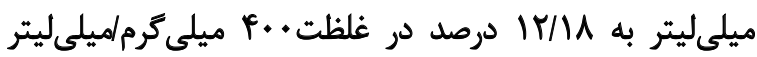

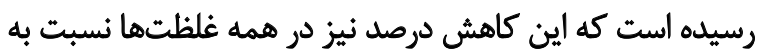

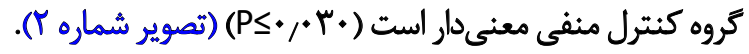

ميدهد كه عصاره زنجبيل، توان زيستى سلولهاي بنيادى

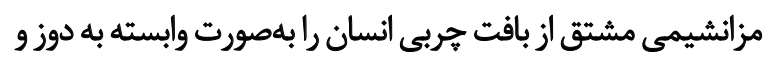

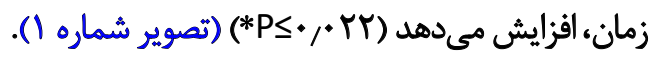

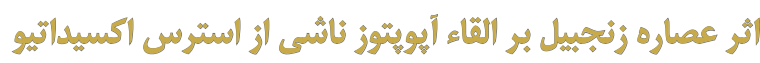

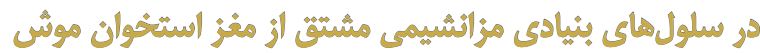
صحرإيى

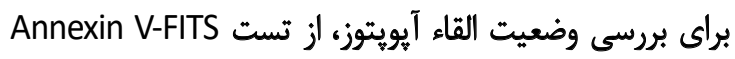

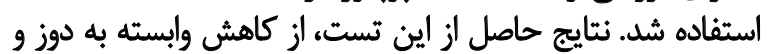

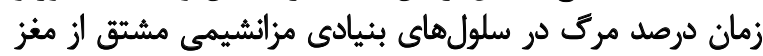

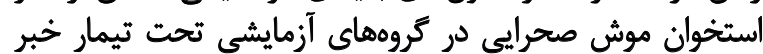



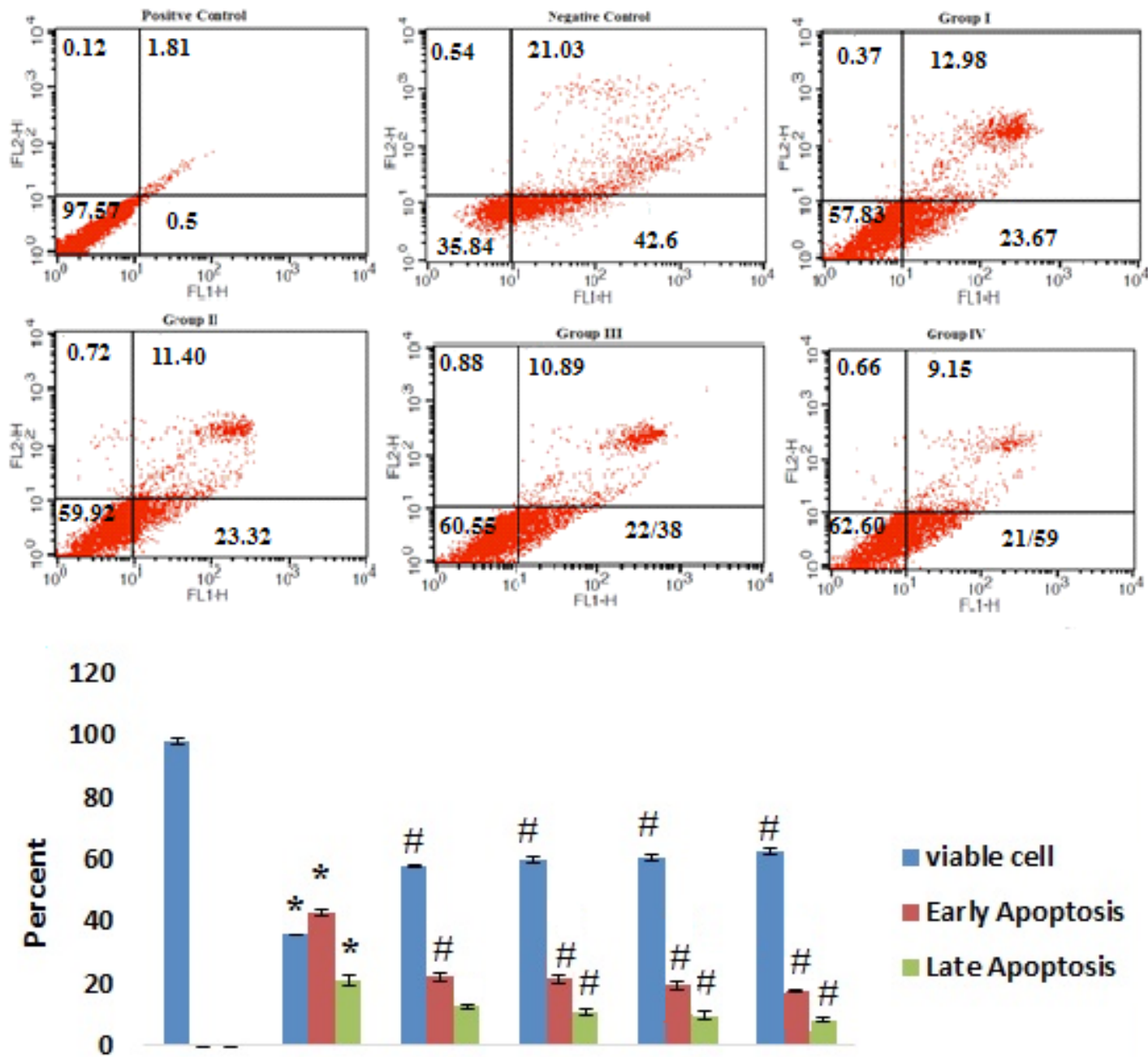

$-20$

Control+ Control- group I group II group III group IV

Groups

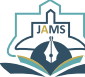

تصوير rا. درصد سلولهايى زنده، آيويتوز اوليه و آيويتوز انتهايى در سلولهاي بنيادى مزانشيمى مشتق از مغز استخوان موش صحرايى تحت تيمار با غلظتهاى

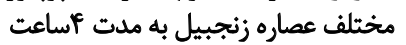

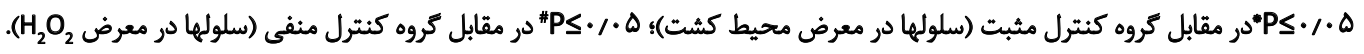

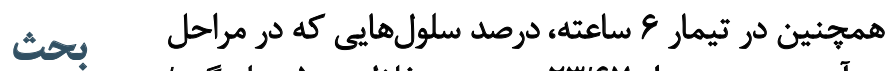

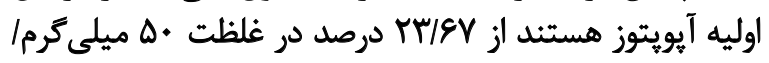

طي فعاليتهاى نرمال سلولهاي به كارگرفته شده در سلول

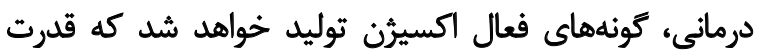

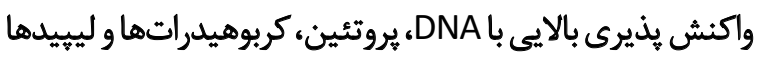

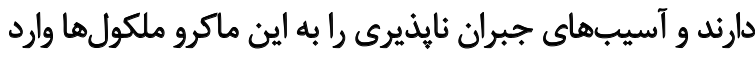

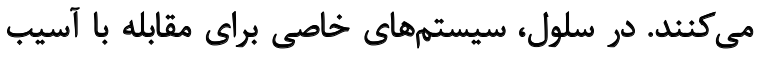

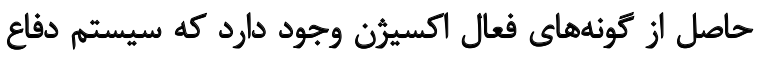

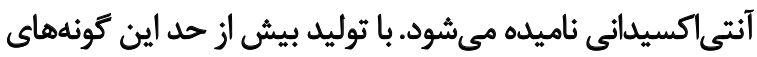

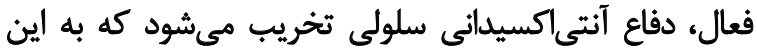

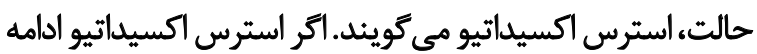

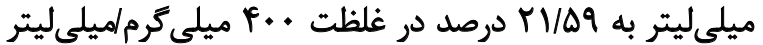

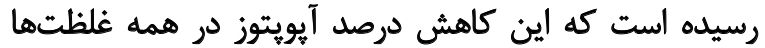

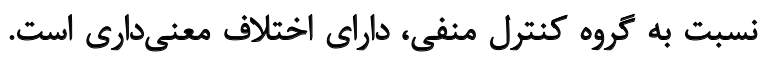

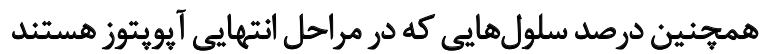

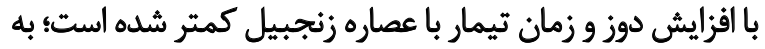

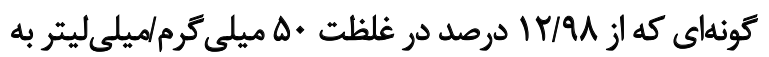

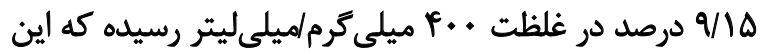

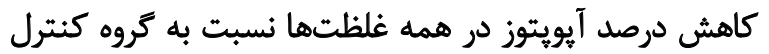

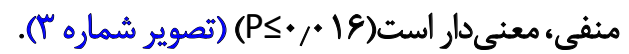


عصاره زنجبيل، راهكار جديدى در راستاى افزايش بقا و بهبود

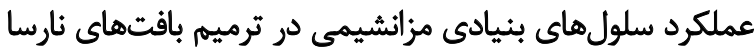

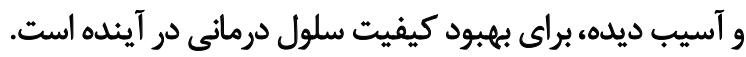

مالاحظات اخلاقي

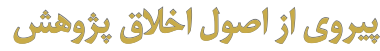

اين مطالعه با كد اخلاق IR.IAU.SHK.REC.1397.028 به دائ تصويب كميثه اخلاق معاونت يثروهشى دانشكاه آزاد اسلامى واحد

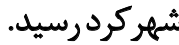

$$
\text { Ito wo so }
$$

اين مقاله، از يايان نامه كارشناسى ارشد نويسنده اول، در كروه

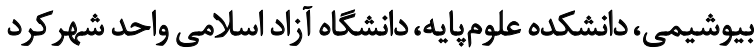

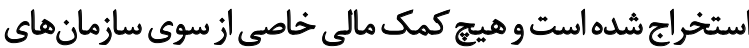

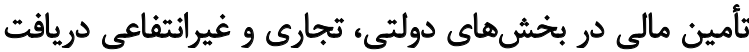

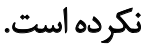

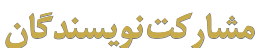

تمام نويسندكان در طراحى، اجرا و نكارش همه بخشهاى ئروهش حاضر مشاركت داشتهاند.

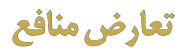

بنابر اظهار نويسندًان اين مقاله تعارض منافع ندارد.

$$
\text { 管 }
$$

بدين وسيله از معاونت محترم يزوهشى دانشعاه آزاد واحد

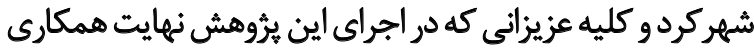
را داشتند، كمال تشكر و قدردانى به عمل مئ مي آيد.
يافت، آسيبهاي اكسيداتيو به بيوملكولهاى حياتى وارد مي آيد

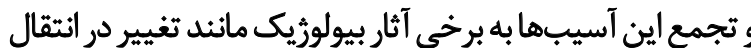

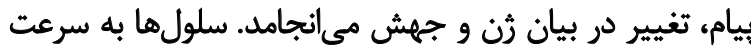

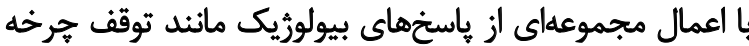

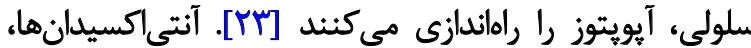

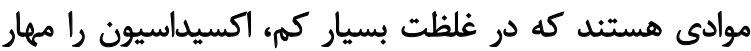

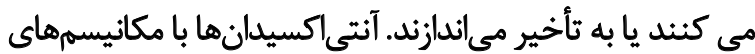

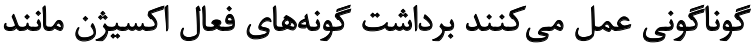

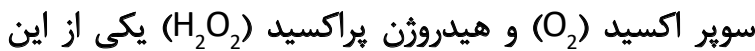

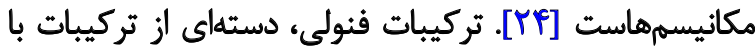

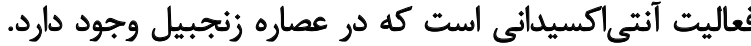

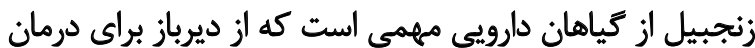

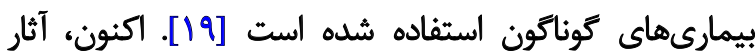

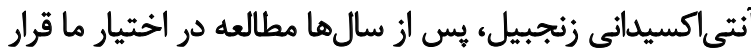

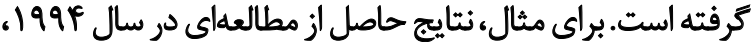

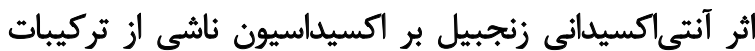

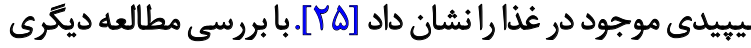

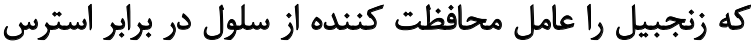

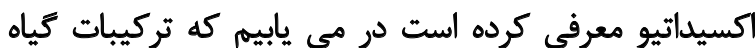

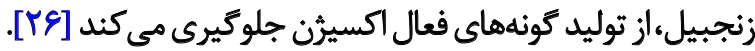
بررسى آثار آنتى اكسيداني و ضد التهابي زنجبيل و مشتئقات آن

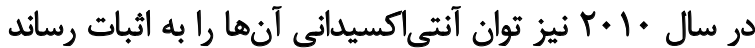

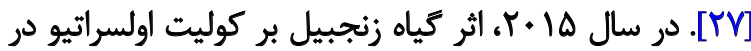

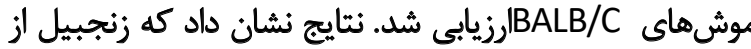

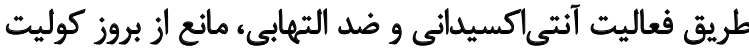

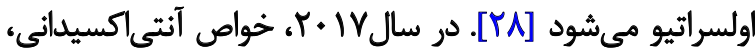

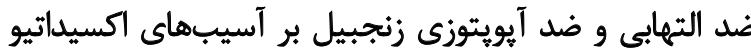

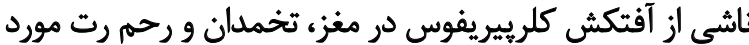

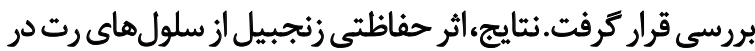

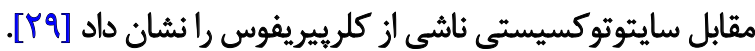

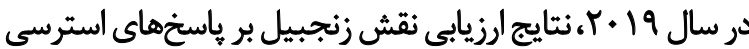

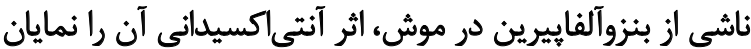

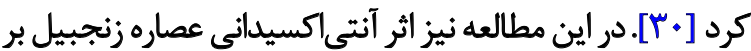

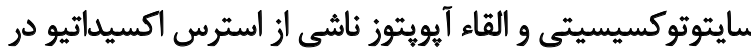

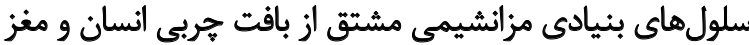

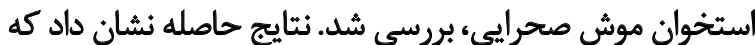

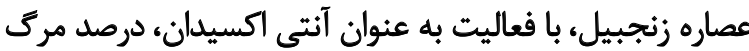

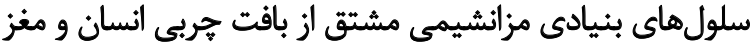

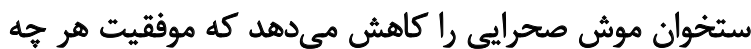

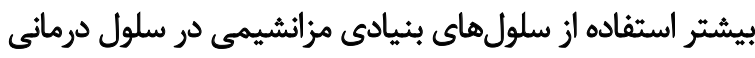
را تضمين خواهد كرد. نتيجهيرى

ي ييش درمان يا درمان مكمل سلولهاى بنيادى مزانشيمى با 


\section{Refrences}

[1] Le Blanc K, Rasmusson I, Sundberg B, Götherström C, Hassan $M$, Uzunel $M$, et al. Treatment of severe acute graft-versushost disease with third party haploidentical mesenchymal stem cells. Lancet. 2004; 363(9419):1439-41. [DOI:10.1016/S01406736(04)16104-7][PMID]

[2] Kuo TK, Hung SP, Chuang CH, Chen CT, Shih YRV, Fang SCY, et al. Stem cell therapy for liver disease: parameters governing the success of using bone marrow mesenchymal stem cells. Gastroenterology. 2008; 134(7):2111-21. [DOI:10.1053/j.gastro.2008.03.015] [PMID][PMCID]

[3] Patel AN, Genovese J. Potential clinical application of adult human mesenchymal stem cell (Prochymal) therapy. Stem Cell Cloning. 2011; 4:61-72. [DOI:10.2147/SCCAA.S11991]

[4] Nassiri AsI M, Aali E. [Review on the mesenchymal stem cells and their potential application in regenerative medicine (Persian)]. J Qazvin Univ Med Sci. 2018; 21(6):74-89. [DOI:10.29252/ qums.21.6.89]

[5] Pournasr Khakbaz B, Baharvand H. [Human mesenchymal stem cells and their clinical application (Persian)]. J Iran Anat Sci. 2007; 5(19):157-206. https://www.sid.ir/en/journal/ViewPaper. aspx?id=113590

[6] Parson AB. The proteus effect: Stem cells and their promise for medicine. Washington, D.C.: Joseph Henry Press; 2004. [DOI:10.1172/JCI25763]

[7] Song L, Tuan RS. Transdifferentiation potential of human mesenchymal stem cells derived from bone marrow. FASEB J. 2004; 18(9):980-2. [DOI:10.1096/fj.03-1100fje][PMID]

[8] Oubari F, Amirizade N, Mohammadpour H, Nakhlestani M, Nikougoftar Zarif M. [The important role of FLT3-L in ex vivo expansion of hematopoietic stem cells following co-culture with mesenchymal stem cells (Persian)]. Cell Journal (Yakhteh). 2015; 17(2):20110. [DOI:10.22074/cellj.2015.3715]

[9] Oubari F, Nikougoftar Zarif M, Amirizadeh N, Shaiegan M, Atarodi $\mathrm{K}$, Nakhlestani M, et al. [Isolation and expansion of Mesenchymal Stem cells from placenta (Persian)]. Sci J Iran Blood Transfus Organ. 2013; 10:222-30. http://bloodjournal.ir/article-1-791-en. html

[10] Dehghani Fard A, Saki N, Ahmadvand M, Mahmoodinia Maymand $M$, Mosahebi Mohammadi M, Soleimani M. [Mesenchymal stem cell biology, application and its role in regenerative medicine (Persian)]. Sci J Iran Blood Transfus Organ. 2012; 8(4):306-20. http://bloodjournal.ir/article-1-586-en.html

[11] Ryan JM, Barry FP, Murphy JM, Mahon BP. Mesenchymal stem cells avoid allogeneic ejection. J Inflamm (Lond). 2005; 2(8):1-11. [DOI:10.1186/1476-9255-2-8][PMID][PMCID]

[12] Nasiri F, Amiri F, Mohammadipour M, Molaei S, Habibi Roudkenar $\mathrm{M}$, Jalili MA. $\left[\mathrm{H}_{2} \mathrm{O}_{2}\right.$-preconditioned mesenchymal stem cell regenerative effects on acute liver failure mice (Persian)]. Sci J Iran Blood Transfus Organ. 2015; 12(2):111-24. http://bloodjournal.ir/ article-1-916-en.html

[13] Baksh D, Song L, Tuan RS. Adult mesenchymal stem cells: Characterization, differentiation and application in cell and gene therapy. J Cell Mol Med. 2004; 8(3):301-16. [DOI:10.1111/j.1582-4934.2004. tb00320.x]
[14] Chapel A, Bertho JM Bensidhoum M, Fouillard L, Young RG, Frick $\mathrm{J}$, et al. Mesenchymal stem cells home to injure tissues when coinfused with hematopoietics cell to treat at radiation, inducedmulti, organfailure syndrome. J Gene Med. 2003; 5(12):1028-38. [DOI:10.1002/jgm.452][PMID]

[15] Marquez-Curtis LA, Janowska-Wieczork A, McGann LE, Elliott JAW. Mesenchymal stromal cells derived from various tissues: Biological, clinical and cryopreservation aspects. Cryobiology. 2015; 71:181-97. [DOI:10.1016/j.cryobiol.2015.07.003][PMID]

[16] Nasir GA, Mohsin S, Khan M, Shams S, Ali G, Khan SN, et al. Mesenchymal stem cells and Interleukin-6 attenuate liver fibrosis in mice. J Transl Med. 2013; 11(3):78-97. [DOI:10.1186/1479-5876-11-78] [PMID][PMCID]

[17] Bahmani M, Saki K, Shahsavari S, Rafieian-Kopaei M, Sepahvand $R$, Adineh A. Identification of medicinal plants effective in infectious diseases in Urmia, northwest of Iran. Asi Paci J Trop Biomed. 2015; 5(10):858-64. [DOI:10.1016/j.apjtb.2015.06.004]

[18] Dadfar F, Hosseini S. E, Bahaoddini A. [A review of phytochemical, pharmacological and physiological properties of ginger (zingiber officinale) (Persian)]. Clin Excell. 2014; 3(1):72-86. http://ce.mazums. ac.ir/article-1-133-en.html

[19] Haksar A, Sharma A, Chawla R, Kumar R, Arora R, Singh S, et al. Zingiber officinale exhibits behavioral radioprotection against radiation Pharmacol Biochem Behav. 2006; 84(2):179-88. [DOI:10.1016/j. pbb.2006.04.008][PMID]

[20] Stoilova I, Krastanov A, Stoyanova A, Denev P, Gargova S. Antioxidant activity of a ginger extract (Zingiber officinale). Food Chem 2007; 102(3):764-70. [DOI:10.1016/j.foodchem.2006.06.023]

[21] Mirazi N, Karami Z. [The protective effect of hydroalcoholic extract from rhizome of Zingiber officinale $\mathrm{L}$. on carbon tetrachlorideinduced hepatic injury in male rat (Persian)]. J Kashan Univ Med Sci (FEYZ). 2016; 20(4):297-305. http://feyz.kaums.ac.ir/article1-3125-en.html

[22] Johari H, Sharifi E, Delirnasab F, Hemayatkhah V, Kargar H, Nikpoor M. [The effect of hydro-alcoholic extracts of ginger on lead detoxification of kidney in the immature wistar rats (Persian)]. J Rafsanjan Uni Med Sci. 2013; 12(6):417-24. http://journal.rums.ac.ir/article1-5290-en.htm

[23] Khoshtabiat L, Mahdavi M. [The role of oxidative stress in prolif eration and cell death (Persian)]. J Mazandaran Univ Med Sci. 2015 25(127):130-45. http://jmums.mazums.ac.ir/article-1-5946-en.htm

[24] Halliwell B. Free radicals and antioxidants - quo vadis? Trends Pharmacol Sci. 2011; 32(3):125-30. [DOI:10.1016/j.tips.2010.12.002]

[25] Aeschbach R, Löliger J, Scott BC, Murcia A, Butler J, Halliwell B, et al. Antioxidant actions of thymol, carvacrol, 6-gingerol, zingerone and hydroxytyrosol. Food Chem Toxicol. 1994; 32(1):31-6. [DOI:10.1016/0278-6915(84)90033-4][PMID]

[26] Kim JK, Kim Y, Na KM, Surh AJ, Kim TY. Gingerol prevents UVB induced Ros production and cox-2 expression invitro and invivo. Free Rad Res. 2007; 41(5):603-14. [DOI:10.1080/10715760701209896] [PMID]

[27] Dugasani S, Pichika MR, Nadarajah VD, Balijepalli MK, Tandra S, Korlakunta JN. Comparative antioxidant and anti-inflammatory effects of [6]-gingerol,[8]-gingerol,[10]-gingerol and [6]-shogaol. J Ethnopharmacol. 2010; 127(2):515-20. [DOI:10.1016/j.jep.2009.10.004] [PMID] 
[28] Ajayi BO, Adedara IA, Farombi EO. Pharmacological activity of 6gingerol in dextran sulphate sodium-induced ulcerative colitis in BALB/c mice. Phytother Res. 2015; 29(4):566-72. [DOI:10.1002/ ptr.5286][PMID]

[29] Abolaji AO, Ojo M, Afolabi TT, Arowoogun MD, Nwawolor D, Farombi EO. Protective properties of 6-gingerol-rich fraction from Zingiber officinale (Ginger) on chlorpyrifos-induced oxidative damage and inflammation in the brain, ovary and uterus of rats. Chem Biol Interact. 2017; 270:15-23. [DOI:10.1016/j.cbi.2017.03.017]

[30] Ajayi B. O, Adedara I. A. 6-Gingerol abates benzo [a] pyrene-induced colonic injury via suppression of oxido-inflammatory stress responses in BALB/c mice. Chemico-biological interactions 2019; 307:1-7. [DOI:10.1016/j.cbi.2019.04.026] 
This Page Intentionally Left Blank 